DOI:10.30842/ielcp230690152330

В. В. Зельченко

(Санкт-Петербургский государственный университет)

\title{
PUELLAE POPULARES (HOR. CARM. II, 13, 25)
}

В оде Горация II, 13, 24-25 Сапфо, исполняя свои песни перед благодарной аудиторией теней в Аиде, queritur puellis de popularibus. Queritur - характерное слово для любовных жалоб, но в чем пуанта эпитета populares ('соотечественницы, землячки')? Р. Г. М. Нисбет и М. Хаббард предполагали здесь двусмысленный намек на лесбийскую любовь, что является лексикологическим анахронизмом: любовь между женщинами не ассоциируется в античности с Лесбосом по меньшей мере до II в. н. э. Bo fr. 96 Voigt (и, с большой долей вероятности, также во fr. 94) Сапфо сетует о подруге, покинувшей Митилены - как обычно считают, ради замужества в чужих краях. Возможно, слова queritur puellis de popularibus (sc. de puellis, qui olim suae populares fuerunt, nunc non sunt) являются реминисценцией этих и подобных им сапфических напутственных песен (propemptika).

Ключевые слова: Гораций, Сапфо, Алкей, popularis, напутственное стихотворение

V. V. Zeltchenko

(St. Petersburg State University)

\section{Puellae populares (Hor. Carm. II, 13, 25)}

In Hor. Carm. III, 13, 24-25 Sappho, performing her songs for the ghosts in the Underworld, queritur puellis de popularibus. Queritur is the right word for a love complaint, but what is the exact meaning of populares ('members of the same community, fellow citizens')? R. G. M. Nisbet and M. Hubbard presume a double entendre («Lesbians in more senses than one») which seems impossible because love between women is never associated with Lesbos before II century AD. In fr. 96 Voigt (and, probably, in fr. 94 too) Sappho complains about a beloved girl who is leaving Mytilenae - for the reasons of marriage abroad, as it is generally supposed. The paper argues that queritur puellis de popularibus (sc. de puellis, qui olim suae populares fuerunt, nunc non sunt) is a reminiscence of such Sapphic propemptika.

Key words: Horace, Sappho, Alcaeus, popularis, propemptikon

Хрестоматийная ода на падение дерева (II, 13) отчетливо делится на две половины, во второй из которых развит мотив Элизиума поэтов. Если бы проклятый ствол все-таки рухнул на Горация, тот увидел бы подземное царство и услышал Сапфо и Алкея (21 sqq.): 
Quam paene furvae regna Proserpinae

et iudicantem vidimus Aeacum

sedesque descriptas piorum et

Aeoliis fidibus querentem

Sappho puellis de popularibus, et te sonantem plenius aureo,

Alcaee, plectro dura navis, dura fugae mala, dura belli.

Utrumque sacro digna silentio

mirantur umbrae dicere, sed magis

pugnas et exactos tyrannos

densum umeris bibit aure volgus.

Quid mirum, ubi illis carminibus stupens

demittit atras belua centiceps

auris et intorti capillis

Eumenidum recreantur angues?

Quin et Prometheus et Pelopis parens

dulci laborem decipitur sono

nec curat Orion leones

aut timidos agitare lyncas.

Картина выступления двух лесбосских лириков перед бесплотной, но отнюдь не бесчувственной аудиторией позволяет Горацию перейти к утверждению собственной поэтической генеалогии и даже к литературно-критическим декларациям:

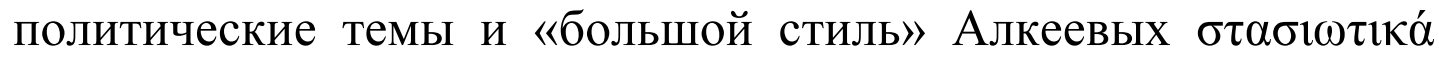
поражают загробную публику сильнее, чем любовные песни Сапфо. Впрочем, как удачно сформулировала Дженни Стросс Клэй, две последние строфы, в которых чарующая сила поэзии связывается со сладкими звуками (dulci sono), а не с содержанием, подводят итоговый баланс, воздавая равные почести обоим предшественникам ${ }^{1}$. Сравнительная характеристика

${ }^{1}$ Strauss Clay 2010: 135-137 (ранее схожую мысль высказывал О. Дёнт: Dönt 1979: 416). Еще один довод в пользу равновесия нашел Виченцо Ди Бенедетто (Di Benedetto 2005: 8-10): Алкей sonat plenius, однако к Сапфо восходит сама сцена пения перед тенями (имеется в виду недавно опубликованный PKöln 21352, 11. 1-8). Дадим краткий


пытались уйти от упрощающего «Гораций ценит Алкея больше, чем Сапфо»: сохраняя пиетет к Сапфо и полемизируя скорее с еe 
Сапфо и Алкея (на сей раз включающая и Архилоха) будет затем повторена в Epist. I, 19, 28-31 - mutatis mutandis и в полемически-самооправдательном контексте, которого наша ода лишена, но с тем же подчеркиванием большей значительности алкеевских тем (res и ordo) ${ }^{2}$ :

Temperat Archilochi musam pede mascula Sappho, temperat Alcaeus, sed rebus et ordine dispar, nec socerum quaerit, quem versibus oblinat atris, nec sponsae laqueum famoso carmine nectit.

Нас будут занимать те строки оды II, 13, в которых говорится о содержании песни Сапфо (23-24). Античная экзегеза объясняет их курьезно: queritur autem Sappho a puellis civibus suis, quod $\Phi \alpha ́ \omega v<\alpha>$ ament [odem non ament M], quem ipsa diligebat amens (Порфирион; у Псевдо-Акрона вариация того же текста: ...quod non amarent, quem ipsa diligebat). Комментаторы Нового времени словно бы сосредоточились на том, чтобы исправить ошибку Порфириона: большинство примечаний к этому месту объясняют, что под queritur имеется в виду 'сетует на неразделенную любовь, ${ }^{3}$. Это само по себе резонно (речь действительно идет о любовных стихах, обращенных к девушкам, а не о проклятиях соперницам), однако одно слово в этих строках останавливает внимание: populares. Это сильный эпитет, означающий 'принадлежащие к тому же populus, соотечественницы'. Конечно, popularis в этом значении не всегда имеет гражданственные коннотации и часто может переводиться простым 'земляк': к примеру, Овидий говорит, что Ниобу ничему не научила судьба Арахны, eе popularis (Met. VI,

устоявшимся образом, поэт тем не менее подчеркивает свою ориентацию на Алкея, чтобы отмежеваться от «сапфических» неотериков (La Penna 1972: 209-210); Гораций вообще против подобных сопоставлений, они кажутся ему схематическими и редукционистскими (Feeney 2002: 9-11); предпочтения, которые выказывают не истинные ценители, но densum umeris volgus, описаны с нотой иронии: речь идет не о собственном выборе поэта, а о том, чего ждет от него публика (Davis 1991: 85-86; Feeney 1993: 49-50; Woodman 2002: 54-55; в этом месте русскому читателю вспоминается толкование пушкинского «Памятника» М. О. Гершензоном: Гершензон 2000: 38-41).

${ }^{2}$ Трудное ordo мы вслед за С. К. Егоровой (Egorova 2006) понимаем как социальный статус.

3 Для примера процитируем Каспара Орелли: «querentem: quod sibi in amore non responderent» (Orelli - Baiter 1850: 284). 
150). Метафорически popularis применимо даже к животным; так, согласно Плинию, в глирариях можно держать вместе только сонь, пойманных в одном лесу, иначе они будут драться: non congregare $<$ se $>$ nisi populares eiusdem silvae (VIII, 224). Ho почему Гораций прилагает к героиням сапфической поэзии такое определение?

Как кажется, первым эту проблему осознал Д. Л. Пейдж: в его обзоре тем и сюжетов Сапфо раздел, посвященный разного рода инвективам, озаглавлен двумя горацианскими строками (24-25) и снабжен примечанием: «I do not see how we can determine exactly what he meant by popularibus» (Page 1955: 133). Спустя два десятилетия Робин Нисбет и Маргарет Хаббард поставили вопрос ребром: «What would it matter if these girls were foreigners or resident aliens?» (Nisbet - Hubbard 1978: 216).

В том, что это недоумение не наиграно и перед нами реальная трудность, убедит эксперимент. Представим себе фразу «В наследии Ахматовой немало любовных стихов, обращенных $\kappa$ соотечественникам», и ее последние слова наверняка покажутся нам нелепостью. С другой стороны, фраза «В стихотворении “Город пышный, город бедный..." Пушкин воспевает красоту неизвестной землячки», хоть и не особенно богата смыслом, но редакторского протеста не вызывает - потому что обладательница «маленькой ножки и локона золотого» ходит по тем же петербургским улицам, что поэт, т. е. их принадлежность одному и тому же городу эксплицитно проговаривается в тексте. Чего-то подобного мы, очевидно, должны ожидать и от горацианской Сапфо.

По версии самих Нисбета и Хаббард, слово populares имеет в виду лесбийскую любовь: героини стихов Сапфо, как и она сама, «were Lesbians in more senses than one». В качестве параллели для подобного double entendre предлагается mascula Sappho из уже упомянутого пассажа Epist. I, 19, $28^{4}$.

Об этих материях непросто говорить так, чтобы не показаться prude: недаром участники двухвековой дискуссии о

\footnotetext{
${ }^{4}$ По нашему мнению, решающий вклад в истолкование этого пассажа, «одного из самых спорных во всей латинской литературе» (Fraenkel 1957: 342), был сделан А. Куккьярелли, который детально обосновал синтаксическую связь pede mascula: Cапфо взяла от Архилоха только стихотворные размеры, но наполнила их собственным - женским содержанием, оказавшись, таким образом, «мужской лишь в том, что касается ритма» (Cucchiarelli 1999; там же перечислены его предшественники).
} 
«mascula Sappho» регулярно обвиняли друг друга то в анахронически-фривольных фантазиях, то, наоборот, в ханжестве, мешающем признать очевидное. Не желая ни оспаривать, ни затушевывать то обстоятельство, что Сапфо для Горация певица любви к девушкам (это, в конце концов, прямо сказано в тексте оды), заметим, что двусмысленность, которую Нисбет и Хаббард усматривают в populares, неприемлема по простым лексикологическим соображениям. Как известно, любовь между женщинами начинает ассоциироваться с Лесбосом и его обитательницами, по самой щадящей оценке, не ранее эпохи Антонинов ${ }^{5}$. Первое свидетельство, и то сопряженное с оговорками, отыскивается в Luc. Dial. mer. 5, 2: на Лесбосе, как говорят, есть мужеподобные гетеры, которые, не желая терпеть мужчин, сходятся с другими женщинами ${ }^{6}$. Для полноценного же употребления этого прилагательного в постулируемом Нисбетом и Хаббард смысле приходится ждать Х в. н. э., а именно схолия Арефы к «Педагогу» Климента Александрийского (III, 3, 21; vol. I, p. 337, 3-4 Stählin) ${ }^{7}$; к тому же, как убедительно показал Альфред Кэмерон (Сameron 1998: 148-149), филологическая маргиналия Арефы всецело ориентируется на место из Лукиана, а вовсе не отражает идиоматику его времени. Таким образом, предполагать подобный намек для поэта I в. до н. э. было бы модернизацией ${ }^{8}$.

Это заставляет нас, признавая законным поставленный Нисбетом и Хаббард вопрос, указать на другое его решение ${ }^{9}$.

5 «Neither the island nor the people of Lesbos are associated with 'lesbianism' in our sense of the term before the second century AD» (Halperin 2002: 231).

${ }^{6} \mathrm{O}$ том, что это изолированное упоминание, обусловленное сюжетом диалога (в нем обсуждаются вкусы вымышленной героини, Мегиллы родом с Лесбоса), не годится на роль classicus testis, см.: Jocelyn 1980: 48, n. 66.

7 На этот схолий, дошедший до нас в автографе, впервые обратил внимание еще Ф. Г. Велькер (Welcker 1845: 86, Anm. 14), чье наблюдение заново ввел в научный оборот А. Ч. Кассио (Cassio 1983).

${ }^{8}$ К сожалению, современные исследователи нередко попадаются в эту ловушку; свежий пример: Ingleheart 2019: 208-209, 220 (и ранее у того же автора: Ingleheart 2010: 297).

9 Лаконичное несогласие с версией Нисбета и Хаббард («non credo») выражает Элиза Романо (Romano 1991: 685), которая, однако, предлагает видеть в puellae populares «девушек, принадлежащих к тому же фиасу». Напомним, что сапфический фиас - не более чем исследовательский конструкт; см., напр.: «The word thiasos does not occur in her extant verses, and the recent reluctance to push the evidence to such a 
Перечисление алкеевских тем в ст. 27-28 - в соответствии с излюбленным у Горация тропом синекдохи, с предпочтением деталей обобщению - по крайней мере в одном случае (dura navis mala) намекает на вполне определенные стихи. Что если и говоря о песнях Сапфо, Гораций не дает их общую характеристику, но указывает на конкретный мотив?

Этот мотив отыскивается без особого труда. В Sapph. fr. 96 Voigt лирическая героиня утешает Аттиду в их общем горе: любимая подруга оставила Лесбос ради Сард (vv. 1, 6). Сапфо прославляет красоту уехавшей, говорит об испытанных вместе радостях, наконец, уверяет, что та продолжает думать об Аттиде и скорбит о разлуке. Причина отъезда в дошедшем тексте не названа, но гипотеза о замужестве кажется естественной и предлагалась, с разной степенью осторожности, множеством комментаторов. C fr. 96 часто сопоставляется fr. 94 Voigt, дошедший в том же Берлинском пергамене VI в. Этот фрагмент написан от первого лица и от имени самой Сапфо: здесь мы вновь имеем дело с расставанием двух подруг-возлюбленных.

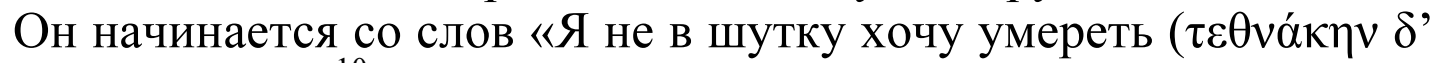
$\dot{\alpha} \delta \delta ́ \lambda \omega \varsigma \theta \varepsilon \dot{\varepsilon} \lambda \omega){ }^{10}$; Сапфо вспоминает о том, как - одновременно и скрывая собственное горе от подруги, и давая читателю почувствовать его (эта тонкая психологическая игра создает эмоциональный фон фрагмента) - великодушно утешала уезжаю-

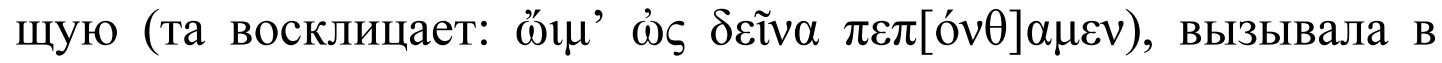
памяти их общее прошлое, желала счастливого пути и просила

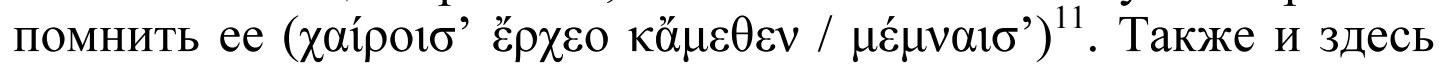
толкователи, восстанавливая сюжетную ситуацию, чаще всего предполагают выход замуж «in a faraway place» (Ferrari 2010:

degree of ritual formality in order to explain Sappho's poetry is salutary» (MacLachlan 1997: 162). Наконец, У. С. М. Николл в поисках актуальных политических подтекстов оды II, 13 предложил совершенно неожиданную интерпретацию: Гораций намекает на то, что в правление Августа эскапистская любовная поэзия - более безопасный удел, чем песни о тираноборческих битвах (Nicoll 1986: 605-606; Николл не упоминает специально о эпитете populares, однако, судя по настойчивому цитированию ст. 25, рассматривает его как довод в свою пользу). ${ }^{10}$ Произносит ли это Сапфо или покидающая ее девушка, спорно (недавнее воскрешение второй точки зрения, которой придерживался первый публикатор фрагмента В. Шубарт: Larson 2010: 179-180).

${ }^{11}$ Сходство с прощальными словами Навсикаи упльвающему Одиссею (Od. VIII, 461) отмечено В. Шадевальдтом (Schadewaldt 1936: 367). 
137) ${ }^{12}$. Впрочем, последнее обстоятельство нам, пожалуй, даже не важно: существенен сам мотив расставания, вызванного отъездом из Митилен, а этот мотив несомненно представлен как минимум во fr. 96. Сапфо в своих стихах сетует о populares, которые перестали ими быть - именно на это, по нашему мнению, намекает Гораций.

Насколько важна эта тема в сапфическом корпусе, заслуживает ли она того, чтобы представительствовать за все творчество Сапфо? Следы античной рецепции Sapph. fr. 94 и 96 засвидетельствованы: в IV в. до н. э. их глубокое влияние демонстрирует поэма Эринны «Прялка»- плач по подруге Бавкиде, которая покинула родину ради замужества и вскоре умерла $^{13}$. Для нас, однако, показательнее роль этих фрагментов

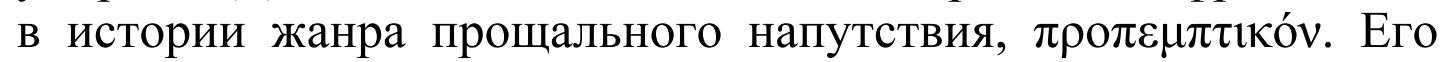
теоретическая разработка представлена у Менандра Лаодикейского, ритора времен Диоклетиана, оставившего два важных трактата по эпидейктическому красноречию; в своих рекомендациях Менандр ориентируется на поэтические образцы не в меньшей мере, чем на ораторские (Russel - Wilson 1981: XXXIXXXIV). В известной монографии Фрэнсиса Кэрнса (Cairns 2007, 50-55 et alibi) показано, как педантичная классификация Менандра, «раскладывающего» жанр по видам (напутствие от от равного к равному, от младшего к старшему, к другу, к начальнику) и по отдельным приемам (в какой момент надо просить отъезжающего остаться, упрекая в жестокосердии, когда пугать опасностями путешествия, когда, наоборот, одуматься и пожелать счастливого пути, каких морских божеств при этом упомянуть) находит прямые соответствия у греческих и римских поэтов от Архилоха и Сапфо до Горация, Вергилия и

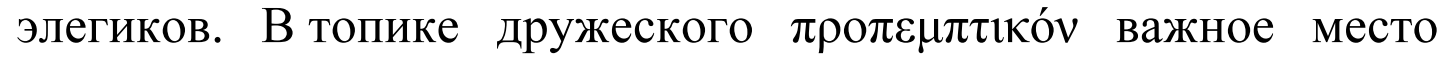

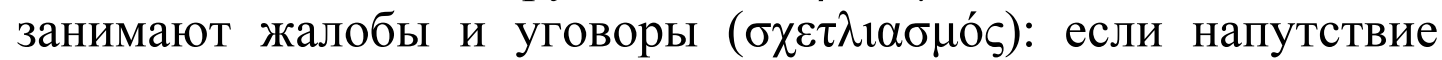
обращено от равного к равному, пишет Менандр, то прово-

\footnotetext{
12 Впервые эту гипотезу высказал тот же Шадевальдт: Schadewaldt 1936: 366. Литература о fr. 94 и 96 необозрима; ср. аналитическую библиографию Д. Э. Гербера (Gerber 1993: 123-130). Вопрос о том, принадлежат ли они к жанру свадебных плачей (см., напр.: Lardinois 2001: 85-88), мы оставляем в стороне.

${ }^{13}$ Связь «Прялки» с Sapph. fr. 94 и 96 впервые подчеркнул С. М. Боура (Bowra 1936: 342); далее см.: Skinner 1982: 269; Rissman 1983: 143, n. 11; Rauck 1989; Rayor 2005; и др. В монументальном комментированном издании фрагментов Эринны (Neri 2003) многочисленные упоминания Sapph. fr. 94 и 96 отыскиваются по указателю.
} 
жающий «будет сетовать, словно претерпев нечто незаслуженное и нежданное, на судьбу и Эротов, что не позволяют узам дружбы оставаться прочными, <..> или обратится к слуша-

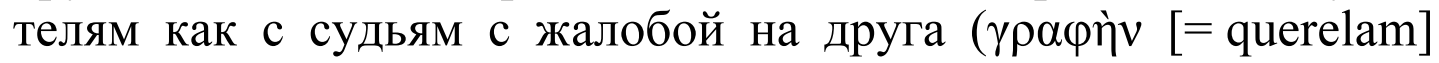

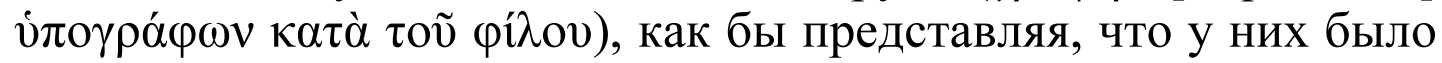
заключено соглашение <..>; далее, если представится случай, он упомянет о совместных упражнениях, о палестре, о том, как они ходили в одни и те же гимнасии...» и т. п. (Menandr. Rhet. III, p. 396 Spengel = p. 128 Russel - Wilson). Параллели к этим

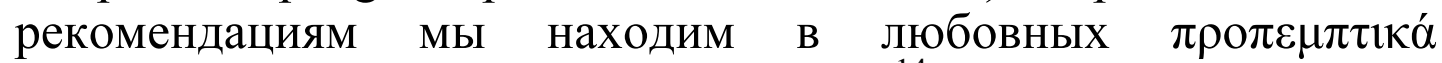
Проперция $(\mathrm{I}, 8)$ и Овидия $(\text { Amor. II, } 11)^{14}$.

Как представляется, Гораций выделяет у Сапфо именно эту

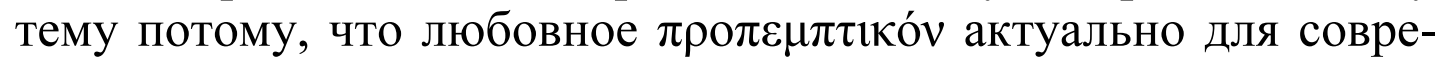
менной ему поэзии и получило в ней эффектное развитие. С другой стороны, упоминание о puellae populares дает поэту возможность выстроить антитезу Сапфо и Алкея: тот в своих стихах тоже «жалуется на земляков», queritur de popularibus но в ином, гражданственном и политическом смысле.

\section{Литература}

Bobrowski, A. 1991: The Propemptikon in the Augustian Poetry (Hor. Od. III 27; Prop. I 8; Ovid. Am. II 11: A Comparative Study). Eos 79, 203-215.

Bowra, C. M. 1936: Erinna's Lament for Baucis. In: Greek Poetry and Life: Essays presented to G. Murray. Oxford, 325-342.

Cairns, F. 2007: Generic Composition in Greek and Roman Poetry. Revised ed. Ann Arbor (1 ed. - 1972).

Cameron, A. 1998: Love (and Marriage) Between Woman. GRBS 39, 143149.

Cassio, A. C. 1983: Post-Classical $\Lambda \varepsilon ́ \sigma \beta ı \alpha 1 . ~ C Q$ n. s. 33, 296-297.

Cucchiarelli, A. 1999: Hor. Epist. 1, 19, 28: pede mascula Sappho. Hermes 127, 328-344.

Davis, G. 1991: Polyhymnia: The Rhetoric of Horatian Lyric Discourse. Berkeley; Los Angeles.

Di Benedetto, V. 2005: La nuova Saffo e dintorni. ZPE 153, 7-30.

Dönt, E. Horaz II, 13. In: Bowersock G et al. (edd.), Arktouros: Hellenic Studies presented to Bernard M. W. Knox on the occasion of his 65. Birthday. Berlin; New York, 413-418.

Egorova, S. 2006: Hor. Epist. I, 19, 29: Alcaeus rebus et ordine dispar, Hyperboreus 12, 195-198.

Feeney, D. 1993: Horace and the Greek Lyric Poets. In: N. Rudd (ed.), Horace 2000: A Celebration. London, 41-63.

${ }^{14}$ Cairns 2007 (по ук., s. v. propemptikon, schetliasmos); Bobrowski 1991; McKeown 1998, 222 ff. 
Feeney, D. 2002: The Odiousness of Comparisons: Horace on Literary History and the Limitations of Synkrisis. In: M. Paschalis (ed.), Horace and Greek Lyric Poetry. Rethymnon, 7-18.

Ferrari, F. 2010: Sappho's Gift: The Poet and Her Community, transl. by B. Acosta Hughes and L. Prauscello. Ann Arbor.

Fraenkel, E. 1957: Horace. Oxford.

Gerber, D. E. 1993: Greek Lyric Poetry Since 1920. Part I: General. Lesbic Poets. Lustrum 35, 7-180.

Gershenzon, M. O. 2000. Izbrannoe. T. 1: Mudrost' Pushkina [Selected Works. Vol. 1: Pushkin's Wisdom]. Moscow, Jerusalem.

Гершензон, М. О. 2000: Избранное. Т. 1: Мудрость Пушкина. М.; Иерусалим.

Halperin, D. M. 2002: The First Homosexuality? In: M. Nussbaum, J. Sihvola (edd.), The Sleep of Reason: Erotic Experience and Sexual Ethic in Ancient Greece and Rome. Chicago, 229-268.

Ingleheart, J. 2010: A Commentary on Ovid, Tristia, Book 2. Oxford.

Ingleheart, J. 2019: Vates Lesbia: Images of Sappho in the Poetry of Ovid. In: Th. S. Thorsen, S. Harrison (edd.), Roman Receptions of Sappho. Oxford, 205-226.

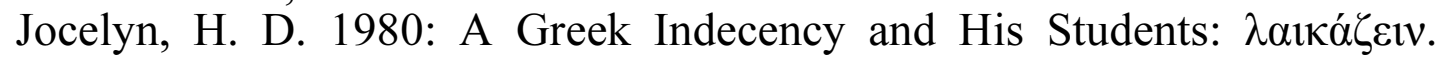
$P C P S$ n. s. 26, $12-66$.

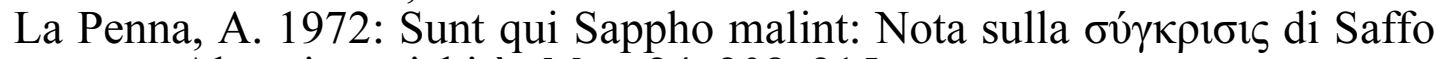
e Alceo in antichità. Maia 24, 208-215.

Lardinois, A. 2001: Keening Sappho: Female Speech Genres in Sappho's Poetry. In: A. Lardinois, L. McClure (edd.), Making Silence Speak: Women's Voices in Greek Literature and Society. Princeton; Oxford, 75-92.

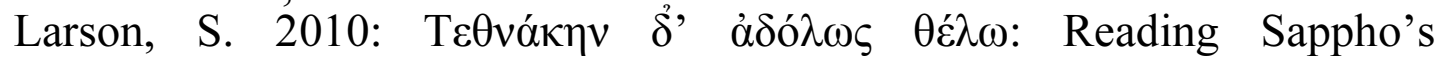
'Confession' through Penelope. Mnemosyne 63, 175-202.

McKeown, J. S. 1998: Ovid. Amores: Text, proleg. and comm. Vol. 3: A Commentary on Book Two. Leeds.

MacLachlan, B. C. 1997: Sappho, in: D. E. Gerber (ed.), A Companion to the Greek Lyric Poets. Leiden, 156-186.

Neri, C. 2003: Erinna: Testimonianze e frammenti. Bologna.

Nicoll, W. S. M. 1986: Horace's Judgement on Sappho and Alcaeus. Latomus 45, 603-608.

Nisbet, R. G. M., Hubbard, M. 1978: A Commentary on Horace: Odes. Book II. Oxford.

Orelli, J. G. - Baiter, J. G. 1850: Q. Horatius Flaccus. Ed. 3 emend. et aucta. T. 1. Turici.

Page, D. L. 1955: Sappho and Alcaeus: An Introduction to the Study of Ancient Lesbian Poetry. Oxford.

Rauck, J. 1989: Erinna's Distaff and Sappho fr. 94. GRBS 30, 101-116.

Rayor, D. J. The Power of Memory in Erinna and Sappho. In: E. Greene (ed.), Women Poets in Ancient Greece and Rome. Norman, 59-71.

Rissman, L. Love as War: Homeric Allusion in the Poetry of Sappho. Königstein.

Romano, E. 1991: Q. Orazio Flacco. Le opere. I: Le Odi, il Carme secolare, gli Epodi. T. 2: Commento. Roma. 
Russel, D. A., Wilson, N. G., 1981: Menander Rhetor, ed. with transl. and comm. Oxford.

Schadewaldt, W. 1936: Zu Sappho. Hermes 71, 363-373.

Skinner, M. B. 1982: Briseis, the Trojan Women, and Erinna. CW 75, 265269.

Strauss Clay, J. 2010: Horace and Lesbian Lyric. In: G. Davis (ed.), $A$ Companion to Horace. Bristol, 128-146.

Welcker, F. G. 1845: Kleine Schriften. II. Bonn, 1845.

Woodman, T. 2002: Biformis vates: The Odes, Catullus and Greek Lyric. In: T. Woodman. D. Feeney (edd.). Traditions and Contexts in the Poetry of Horace. Cambridge, 53-64. 